\title{
The Critical Evaluation of the Vibroacoustic Criteria Used in Poland to Diagnose of Power Transformer Cores
}

\author{
S. BorUCKI*, A. CiChON, T. BOCZAR AND D. ZMARZly \\ Faculty of Electrical Engineering, Automatic Control and Computer Science, Opole University of Technology \\ Prószkowska 76, 45-758 Opole, Poland
}

\begin{abstract}
The subject matter of this article concerns the diagnostic test results of transformer cores by measuring and analysing vibroacoustic signals registered during their normal operation. The main objective of this research study conducted by the authors, the results of which are published in this paper, is a critical analysis of vibroacoustic criteria, which are adopted in Poland nowadays, and based on which, the assessment of the core technical condition is performed. This article presents exemplary results that were obtained on two twin units of type TET 8509 with a power of 40 MVA. The paper specifies diagnosed structures, the measurement system applied, and the currently used methodology to assess the degree of core loosening. To determine the efficacy and assessment accuracy of the applied vibroacoustic criteria, correlation between mechanical vibration measurements of the tested transformer tanks and results obtained by gas chromatography was performed.
\end{abstract}

DOI: 10.12693/APhysPolA.124.391

PACS: 43.40.-r, 43.40.Vn, 43.58.Wc

\section{Introduction}

The power transformers belong to the group of devices that are of strategic importance for the electric power system. Despite the fact that they are characterized by high operational reliability [1], their breakdowns carry very serious technical and economic consequences [2]. Taking into account that the service life of number of parts installed in the system exceeded 30 years, it can be assumed that in the near future there will be a gradual increase in their breakdowns [3].

The main part in the construction of transformers is the core. High reliability of its work depends on the long-term and trouble-free operation of high power network and block units. Operating transformer with a defect in core construction that lasts several months does significantly speed up the aging process of the insulating system, as well as can cause emergency shutdown performed by the gas-flow security unit. Currently, diagnostics of transformer cores operating in the national power system is performed on the basis of the results using the DGA tests of the oil, measuring the magnetizing current and vibroacoustic values $[4,5]$.

The article concerns the assessment of technical condition of transformer cores, based on measurement and analysis of the vibroacoustic signals. The issue is to carry out further research works performed by the authors in the past few years on the implementation and efficient use of this method under industrial conditions [6-13].

The main objective of the research, results of which are presented in this article, is the critical analysis of vibroacoustic criteria, which are adopted currently in Poland.

*corresponding author; e-mail: s.borucki@po.opole.pl
The need to review the vibroacustic method criteria that are used in Poland for many years is driven by, inter alia, technological changes introduced in the structure of the active parts in transformers. These modifications led to changes in frequency parameters and in values of the measured accelerations of the mechanical vibrations transmitted by the tank. For this reason, it is essential to perform correlation tests intended to assess the accuracy of the limit and boundary values that were designated in the last century and are still widely implemented.

\section{Vibroacoustic criteria applied in Poland}

The vibroacoustic method for diagnostics of the transformer cores was implemented in Poland in the 80's of the twentieth century by Energopomiar Company seated in Gliwice [14]. To this day, this method is one of the specialist tests that are recommended in operating instructions $[5,15-17]$. The instructions that are available in Poland recommend that transformer magnetic circuit diagnostics shall be performed, based on the analysis of measured vibrations, examining the effective value of vibration acceleration in the band up to $2500 \mathrm{~Hz}$ and the even-numbered frequency amplitude of the spectral components $(100,200, \ldots, 2500 \mathrm{~Hz})$. First of the mentioned criteria assumes that the effective value of vibration acceleration for operating structure should not exceed the value of $400 \mathrm{~cm} / \mathrm{s}^{2}$. However, the occurrence of accelerations that exceed the maximum value can indicate on damages to the core of the studied device and the need to carry out a detailed overview or repair. The second analysed diagnostic parameter is the even harmonic amplitudes of vibration acceleration in the band 100-2500 Hz. However, in this case, the frequency range of the measured vibroacoustic signals is divided into three distinct groups: 
- vibrations of components of up to $500 \mathrm{~Hz}$, which are considered as parts derived and characterized by the magnetostriction phenomenon,

- vibrations of components from 600 to $1500 \mathrm{~Hz}$, which are considered as parts characterizing the operation of cooling devices,

- vibrations of components of above $1500 \mathrm{~Hz}$, which are considered as generated parts characterizing correct or incorrect operation of the core.

On the basis of recommendations applied in Poland, the assessment of the technical condition of the magnetic circuit of transformers according to the second criterion is performed exclusively on the basis of the amplitude of vibration components in the frequency band from 1500 to $2500 \mathrm{~Hz}$. Such designated frequency values of individual harmonics for which the amplitude exceeds the adopted limit value, shown in Table I, indicate the progress or damage of the core in the monitored structure.

TABLE I

Limit values for even-frequency components of transformer vibration wave spectrum in the range $1500-2500 \mathrm{~Hz}$.

\begin{tabular}{c|c|c|c}
\hline \hline $\begin{array}{c}\text { Strength of } \\
\text { transformer } \\
S[M V A]\end{array}$ & $\begin{array}{c}\text { Core without } \\
\text { any damage }\end{array}$ & $\begin{array}{c}\text { Core with } \\
\text { emerging damages }\end{array}$ & $\begin{array}{c}\text { Damaged } \\
\text { core }\end{array}$ \\
\hline$S \leq 200$ & $a \leq 3 \mathrm{~cm} / \mathrm{s}^{2}$ & $3 \mathrm{~cm} / \mathrm{s}^{2}<a \leq 30 \mathrm{~cm} / \mathrm{s}^{2}$ & $a>30 \mathrm{~cm} / \mathrm{s}^{2}$ \\
$S>200$ & $a \leq 10 \mathrm{~cm} / \mathrm{s}^{2}$ & $10 \mathrm{~cm} / \mathrm{s}^{2}<a \leq 30 \mathrm{~cm} / \mathrm{s}^{2}$ & $a>30 \mathrm{~cm} / \mathrm{s}^{2}$
\end{tabular}

According to recommendations [5, 14], vibroacoustic measurements in power transformers shall be carried out at site of their installation and during normal operation. Depending on dimensions of the unit, the number of measurement positions (6 to 8 ), located symmetrically on the walls of the tank, shall be determined. Registration is carried out using accelerometers and apparatus that allow recording the measured signals on magnetic disk or other storage medium. Then, in laboratory with application software, frequency descriptors shall be designated to compare them with indicators considered as acceptable and boundary.

\section{Characteristics of the tested transformers and the applied measurement methodology}

For the purpose of the research study, the vibro-acoustic testing covered population of more than 40 transformers. These devices were characterized by different nominal parameters and by various operational times. This article presents only exemplary results that were obtained on two twin units of type TET 8509. Basic nominal parameters of the tested transformers are shown in Table II.

The established collaboration with distribution and diagnostic companies made possible to perform vibration measurements on a large population of transformers, as well as to explore the history of their operation. In terms of technical condition assessment of the core mechanical
TABLE II

Technical parameters of the analysed transformers type TET 8509 .

\begin{tabular}{l|c|c}
\hline \hline \multicolumn{1}{c|}{ Technical } & Transformer & Transformer \\
parameters & No. 1 & No. 2 \\
\hline manufacture & ASEA & ASEA \\
type & TET 8509 & TET 8509 \\
power [MVA] & $40 / 27 / 40$ & $40 / 27 / 40$ \\
voltage $[\mathrm{kV} / \mathrm{kV} / \mathrm{kV}]$ & $121 / 16.5 / 6.3$ & $121 / 16.5 / 6.3$ \\
production year & 1975 & 1975 \\
load during the & 23 & 24.7 \\
measurements [MVA] & &
\end{tabular}

structure, the most essential were the test results with gas chromatography in the electric insulating oil. Differential gravimetric analysis (DGA) has allowed the authors to make an initial diagnosis on the actual degree of wear and degradation of the active parts in diagnosed units. Direct correlation of DGA results with indicators registered from vibrations allowed assessing the effectiveness and accuracy of vibroacoustic test criteria currently applicable in Poland. Table III represents the DGA test results of oil samples taken from tank of the tested transformers of type TET 8509.

TABLE III

DGA test results in the oil of transformers of type TET 8509 .

\begin{tabular}{l|c|c}
\hline \hline \multirow{2}{*}{$\begin{array}{c}\text { Indicated gas } \\
\text { components }\end{array}$} & \multicolumn{2}{c}{$\begin{array}{c}\text { Concentration of gas } \\
\text { in the oil sample [ppm] }\end{array}$} \\
\cline { 2 - 3 } & $\begin{array}{c}\text { Transformer } \\
\text { No. 1 }\end{array}$ & $\begin{array}{c}\text { Transformer } \\
\text { No. 2 }\end{array}$ \\
\hline hydrogen $-\mathrm{H}_{2}$ & 1.9 & 3.3 \\
methane $-\mathrm{CH}_{4}$ & 2.2 & 2.9 \\
ethane $-\mathrm{C}_{2} \mathrm{H}_{6}$ & 2.3 & 2.4 \\
ethylene $-\mathrm{C}_{2} \mathrm{H}_{4}$ & 1.7 & 12.1 \\
acetylene $-\mathrm{C}_{2} \mathrm{H}_{2}$ & 1.6 & 2 \\
propane $-\mathrm{C}_{3} \mathrm{H}_{8}$ & 2.1 & 3.7 \\
propylene $-\mathrm{C}_{3} \mathrm{H}_{6}$ & 0.9 & 4.9 \\
butane $-\mathrm{C}_{4} \mathrm{H}_{10}$ & 0 & 0 \\
carbon monoxide $-\mathrm{CO}$ & 63.5 & 108.3 \\
carbon dioxide $-\mathrm{CO}_{2}$ & 1611.7 & 3114.1 \\
air & 25702 & 25356 \\
total combustible gases & 76.2 & 139.6
\end{tabular}

Measurements of vibroacoustic signals in TET 8509 transformers were carried out using mobile measuring and diagnostic system based on Pulse Dyn-XI cassette produced by Bruel\&Kjær, while the analysis of the registered vibrations was performed in Pulse LabShop package.

During the implementation of the measurement procedure, the entire surface of the tank of transformers was dimensioned by vertical-horizontal grid with coordinates in $x$ and $y$ axes. The height of the tank, from the bottom to the top cover, was designated as $h$. Measurements 
were performed in the mid-height of the tank, in the symmetry axes of each of the three phases. In this way, eight data points were obtained: three positions on the side wall from the output of upper voltage bushings (GN), three on the side wall from the output of lower voltage insulators (DN) and one at each position on both sides of the tank. A sketch of measurement point distribution is presented in Fig. 1. Symbols of measurement points from the figure below also refer to the distribution of tables and graphs, presented later in the article.
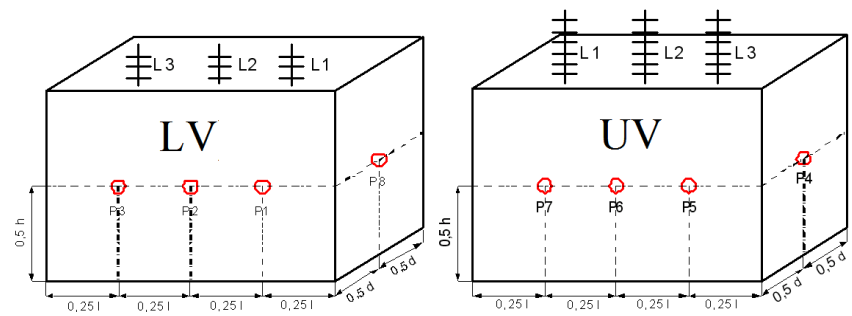

Fig. 1. A sketch of the transformer tank with designated vibration measurement points: $h-$ height, $d l-$ length, $s z$ - width.

\section{Analysis results of the registered vibroacoustic signals}

One of the examples confirming irrelevance for applying in Poland the accepted diagnostic criteria for the vibroacoustic method are, inter alia, results obtained for these two transformers of type TET 8509, analysed in this study. In Tables IV-VI there were summarized values of the measured vibration indicators, which were obtained from registrations performed in each of the eight points located on tanks of these devices.

TABLE IV

Effective values of vibration acceleration of TET 8509 transformers.

\begin{tabular}{c|c|c}
\hline \hline \multirow{2}{*}{$\begin{array}{c}\text { Measuring } \\
\text { point }\end{array}$} & \multicolumn{2}{|c}{$\begin{array}{c}\text { Effective value of vibration acceleration } \\
A\left[\mathrm{~cm} / \mathrm{s}^{2}\right]\end{array}$} \\
\cline { 2 - 3 } & Transformer No. 1 & Transformer No. 2 \\
\hline P1 & 256 & 248 \\
P2 & 231 & 211 \\
P3 & 176 & 247 \\
P4 & $\mathbf{5 3 1}$ & $\mathbf{6 3 6}$ \\
P5 & 323 & 268 \\
P6 & 321 & $\mathbf{6 3 9}$ \\
P7 & 378 & $\mathbf{7 4 5}$ \\
P8 & $\mathbf{7 7 5}$ & $\mathbf{7 1 3}$
\end{tabular}

Based on the analysis of results presented in Tables IV-VI and their comparation to boundary values, it can be stated that transformers of type TET 8509 have defects in core mechanical structure. This statement is particularly true for the unit No. 2. Effective values of
TABLE V

Acceleration values of even harmonic vibrations of the TET 8509 transformer (transformer No. 1).

\begin{tabular}{c|c|c|c|c|c|c|c|c}
\hline \multirow{2}{*}{ Harmonic } & \multicolumn{8}{|c}{ Effective value of vibration acceleration } \\
& \multicolumn{8}{|c}{$A\left[\mathrm{~cm} / \mathrm{s}^{2}\right]$} \\
\cline { 2 - 9 } & P1 & P2 & P3 & P4 & P5 & P6 & P7 & P8 \\
\cline { 2 - 9 } 1500 & 2.7 & $\mathbf{3 . 9}$ & 1.0 & 2.0 & 1.2 & $\mathbf{3 . 8}$ & 1.8 & 11.2 \\
1600 & $\mathbf{4 . 8}$ & 0.9 & 0.6 & 1.7 & 0.6 & 1.7 & 0.7 & $\mathbf{6 . 0}$ \\
1700 & 2.6 & 2.9 & 1.0 & $\mathbf{4 . 9}$ & $\mathbf{6 . 7}$ & 1.9 & 0.7 & $\mathbf{5 . 0}$ \\
1800 & 2.7 & 1.1 & $\mathbf{3 . 4}$ & 1.3 & 2.6 & 1.6 & $\mathbf{6 . 1}$ & 2.7 \\
1900 & 3.0 & 1.7 & 1.3 & 1.2 & 1.0 & 1.3 & 1.9 & 2.2 \\
2000 & 2.8 & 0.8 & 1.4 & 1.3 & 0.7 & 1.0 & 1.4 & 0.9 \\
2100 & $\mathbf{3 . 4}$ & 1.6 & 1.4 & 1.2 & 1.6 & 2.2 & 2.4 & $\mathbf{3 . 3}$ \\
2200 & 3.0 & 1.8 & 1.6 & 1.2 & 0.4 & $\mathbf{3 . 2}$ & 2.1 & 1.2 \\
2300 & 0.8 & 2.3 & 1.2 & 2.7 & 0.7 & 2.1 & 2.8 & 2.5 \\
2400 & 2.8 & 1.2 & 2.8 & 0.7 & 2.4 & 1.4 & 2.1 & 1.3 \\
2500 & 1.4 & 0.7 & 1.5 & 1.6 & 0.5 & 1.0 & 2.9 & 2.6
\end{tabular}

TABLE VI

Acceleration values of even harmonic vibrations of the TET 8509 transformer (transformer No. 2).

\begin{tabular}{c|c|c|c|c|c|c|c|c}
\hline \multirow{2}{*}{ Harmonic } & \multicolumn{7}{|c}{ Effective value of vibration acceleration } \\
\cline { 2 - 9 } & \multicolumn{7}{|c}{ Number of the measurement point } \\
\cline { 2 - 9 } & P1 & P2 & P3 & P4 & P5 & P6 & P7 & P8 \\
\hline 1500 & $\mathbf{1 1 . 8}$ & $\mathbf{7 . 5}$ & $\mathbf{1 4 . 7}$ & $\mathbf{9 . 5}$ & $\mathbf{1 3 . 3}$ & $\mathbf{1 0 . 4}$ & $\mathbf{7 . 1}$ & $\mathbf{6 . 2}$ \\
1600 & $\mathbf{5 . 4}$ & $\mathbf{6 . 7}$ & $\mathbf{1 1 . 6}$ & $\mathbf{3 . 2}$ & 2.0 & $\mathbf{4 . 3}$ & $\mathbf{5 . 1}$ & 2.8 \\
1700 & $\mathbf{5 . 1}$ & $\mathbf{8 . 9}$ & $\mathbf{6 . 9}$ & 0.8 & $\mathbf{8 . 9}$ & $\mathbf{5 . 3}$ & 2.7 & 4.1 \\
1800 & 0.8 & $\mathbf{4 . 3}$ & $\mathbf{1 1 . 1}$ & 1.3 & $\mathbf{4 . 6}$ & 2.7 & 1.5 & 1.8 \\
1900 & 2.8 & $\mathbf{5 . 3}$ & $\mathbf{4 . 4}$ & 0.4 & 2.6 & $\mathbf{4 . 1}$ & 1.7 & $\mathbf{7 . 1}$ \\
2000 & $\mathbf{4 . 1}$ & $\mathbf{3 . 1}$ & $\mathbf{5 . 6}$ & $\mathbf{4 . 3}$ & 1.5 & 1.5 & $\mathbf{5 . 0}$ & 2.1 \\
2100 & $\mathbf{4 . 0}$ & 2.5 & $\mathbf{3 . 6}$ & 2.2 & 1.2 & $\mathbf{5 . 0}$ & 1.9 & $\mathbf{6 . 1}$ \\
2200 & 2.6 & 0.6 & $\mathbf{4 . 5}$ & 1.3 & 2.1 & $\mathbf{4 . 3}$ & 1.7 & 2.6 \\
2300 & 1.4 & $\mathbf{4 . 2}$ & 0.8 & 2.4 & 1.0 & $\mathbf{4 . 7}$ & 2.9 & 2.8 \\
2400 & 2.9 & 2.3 & 0.9 & 2.1 & 2.6 & 1.9 & 1.1 & $\mathbf{6 . 4}$ \\
2500 & 1.0 & 1.1 & $\mathbf{8 . 4}$ & 2.1 & 2.9 & 1.1 & $\mathbf{3 . 1}$ & $\mathbf{3 . 5}$
\end{tabular}

vibration acceleration in the frequency range $5-2500 \mathrm{~Hz}$ in four measurement points (P4, P6, P7, P8) that were designated for this device are significantly higher than the value of $400 \mathrm{~cm} / \mathrm{s}^{2}$. For transformer No. 1 these values are exceeded in points $\mathrm{P} 4$ and $\mathrm{P} 8$. Analysis of acceleration values of harmonic vibrations in frequency range $1500-2500 \mathrm{~Hz}$ indicated damages to the cores of these structures, as well. The adopted boundary value of $3 \mathrm{~cm} / \mathrm{s}^{2}$ was exceeded for these units in all measurement points. For transformer No. 2, failure to comply with the recommended criterion is close to $50 \%$ of the frequency components.

Contrary diagnosis, to the one stated on the basis of vibroacustic tests on magnetic circuit technical condition in transformers No. 1 and 2 shall be indicated on the basis of the results of gas chromatography. Specific gas concentration values presented in Table III are charac- 
terized by relatively low values and do not indicate the occurrence of local overheating or damage to the active part. Analysis of the DGA test history showed that the quantity proportion of individual gases has not changed significantly during several years of operation of these devices, which proves good technical condition of these two monitored structures.

The diagnostic example indicated that the vibroacoustic criteria being adopted in Poland do not allow for effective evaluation of the technical condition of transformer cores. Results from the performed vibration measurements clearly pointed to defects of the cores of TET 8509 transformers and the archival and actual DGA test results entirely excluded this possibility. Similar observations apply to several other transformers, for which, similarly as for the TET 8509 units, the designated vibration descriptors indicate occurrence of defects in their cores. However, DGA test analysis of electrical insulating oil sampled from their tanks, entirely excludes such a possibility.

\section{Summary}

Analysis of effective values of vibration acceleration in the frequency range of $5-2500 \mathrm{~Hz}$ that was performed on industrial structures of different types and strengths has indicated that the designated vibroacoustic indicators oscillate within a very wide range from 10 to $800 \mathrm{~cm} / \mathrm{s}^{2}$. However, considering the DGA test results of the oil in these devices and no indications on the potential damages to their cores that apply to most cases, it can be assumed that the adopted criterion value of $400 \mathrm{~cm} / \mathrm{s}^{2}$ seems to be unfounded. In addition, the performed comparative analysis of effective vibration acceleration values from the transformer operation time has shown that units with few years of operation life are characterized by significantly lower values of this indicator. Analogous conclusions shall be withdrawn on the basis of the analysis of effective vibration acceleration values of individual harmonic spectrum in the range 1500 to $2500 \mathrm{~Hz}$.

Research studies, performed by the authors, implemented on a wide population of transformers operating under industrial conditions have shown that based on the vibroacoustic criteria that are currently recommended in Poland, a unequivocal assessment on the actual condition of mechanical core structure of the analysed transformer unit cannot be made.

Despite the diagnostic criteria applied in the country, it should be stated that the only effective factor determining high efficiency of the vibroacustic method applied in Poland, in terms of technical condition of the mechanical structure of transformer cores is the periodicity in conducting the tests. The methodology allows visualizing the dynamics of changes in time of the designated descriptors, rather than determining only their absolute dimension. This applies to the effective value of vibration acceleration, as well as to the amplitude values of individual harmonic components in the spectrum.

Due to the fact that the development of defects in magnetic circuits is a long-term process, observation of changes in the time of designating the vibroacoustic indicators allows for fast intervention by the inspection services, when the given descriptor increases. Measurements carried out in this manner should therefore protect the strategic devices against main breakdowns, which can lead to their total destruction.

\section{Acknowledgments}

The work was financed with the means from the National Research and Development Center within LIDER program.

\section{References}

[1] J. Maksymiuk, Reliability of Machinery and Electrical Equipment, Warsaw University of Technology, Warszawa 2003 (in Polish).

[2] J. Singh, Y.R. Sood, R.K. Jarial, IEEE El. Ins. Mag. 24, 11 (2008).

[3] CIGRE Technical Brochure, Guide for Life Management Techniques for Power Transformers, No. 227 (2003).

[4] M. Duval, IEEE El. Ins. Mag. 24, 7 (2008).

[5] Framework Manual Operation of Power Transformers, Energopomiar-Elektryka, Gliwice 2012, (in Polish).

[6] T. Boczar, S. Borucki, A. Cichoń, M. Lorenc, Acta Phys. Pol. A 114, A21 (2008).

[7] S. Borucki, T. Boczar, A. Cichoń, Arch. Acoust. 36, 49 (2011).

[8] S. Borucki, T. Boczar, A. Cichoń, Arch. Acoust. 32, Suppl., 291 (2007).

[9] S. Borucki, Acta Phys. Pol. A 116, 277 (2009).

[10] S. Borucki, Acta Phys. Pol. A 120, 571 (2011).

[11] S. Borucki, IEEE Trans. Power Delivery 27, 670 (2012).

[12] D. Wotzka, T. Boczar, P. Fracz, Acta Phys. Pol. A 120, 767 (2011).

[13] D. Wotzka, T. Boczar, Electrotechn. Rev. 86, 74 (2010) (in Polish).

[14] Diagnosis of the Technical Condition of Power Transformers. Principles of Testing and Evaluation Criteria, Energopomiar, Gliwice 1983 (in Polish).

[15] K. Barczak, Bull. Pol. Acad. Sci. Techn. Sci. 59, 409 (2011).

[16] T. Domżalski, Energetyka 4, 172 (2001) (in Polish).

[17] J. Kapinos, problem Notebooks - Electrical Machines 88, 201 (2010) (in Polish). 